\title{
Secondary sclerosing cholangitis in cardiac surgical patients: A complication with a dismal prognosis
}

\author{
Ina Schade, MD, ${ }^{a}$ Dejan Radakovic, MD, ${ }^{\mathrm{a}}$ Jörg Hoffmann, MD, ${ }^{\mathrm{a}}$ Sebastian-Patrick Sommer, MD, PhD, ${ }^{\mathrm{a}}$ \\ Ullrich Stefenelli, MPH, ${ }^{\mathrm{b}}$ Christoph Schimmer, MD, PhD, ${ }^{\mathrm{a}}$ Rainer G. Leyh, MD, PhD, ${ }^{\mathrm{a}}$ and \\ Ivan Aleksic, $\mathrm{MD}, \mathrm{PhD}^{\mathrm{a}}$
}

\begin{abstract}
Objectives: Secondary sclerosing cholangitis in critically ill patients is a rapidly progressing disease leading to biliary fibrosis and cirrhosis. We describe the course of sclerosing cholangitis in critically ill patients after cardiac surgery and compare this with matched patients.

Methods: A retrospective search for "secondary sclerosing cholangitis" and "liver and/or hepatic failure" in all adult patients (aged 18-93 years) who underwent cardiac surgery from April 2007 to March 2016 identified 192 of 8625 patients. Of those, 12 were diagnosed with sclerosing cholangitis in critically ill patients (incidence, $0.14 \%$ ). A 3:1 matching was performed. Laboratory values, pharmacologic requirements, ventilation times, mechanical circulatory support, and endoscopic retrograde cholangiopancreatography studies were extracted from the hospital database.
\end{abstract}

Results: A total of 9 men and 3 women were affected (age 71 years; range, 59.8-75.5 years). Critically ill patients with sclerosing cholangitis required vasoconstrictors and inotropes longer than control patients (norepinephrine 356.5 hours [264.5-621] vs 68 hours [15-132.5], $P=.003$; enoximone 177 hours [124.3-249.5] vs 48.5 hours [12-81 hours], $P<.001$, respectively). Critically ill patients with sclerosing cholangitis had longer intubation time (628.5 hours [377.3-883] vs 25 hours [9.8-117.5]; $P<.001)$ and more surgical revisions (3 [2.5-6] vs 1 [0-2], $P=.003)$ than the matching group. Bilirubin $(23.3 \mathrm{mg} / \mathrm{dL}[14.4-32.9] \mathrm{vs} 1 \mathrm{mg} / \mathrm{dL}$ [0.6-2.7]; $P<.001)$, gamma-glutamyltransferase (1082.3 U/L [259.5-2265.7] vs 53.8 U/L [35.1-146]; $P<.001)$, and alkaline phosphatase (751.5 U/L [372-1722.3] vs $80.5 \mathrm{U} / \mathrm{L}$ [53.3-122]; $P<.001$ ) were higher in critically ill patients with sclerosing cholangitis. One critically ill patient with sclerosing cholangitis underwent successful liver transplantation. A total of 11 patients sclerosing cholangitis died $(92 \%)$ versus 12 patients $(33 \%, P<.001)$ in the control group.

Conclusions: Sclerosing cholangitis in critically ill patients is a fatal complication in patients undergoing cardiac surgery who have a complicated postoperative course with prolonged vasoconstrictor, inotropic, and respiratory therapy, or who require frequent surgical revisions. Liver transplantation remains the only curative option but is often precluded by the age and critical state of patients undergoing cardiac surgery. (J Thorac Cardiovasc Surg 2017;154:906-12)

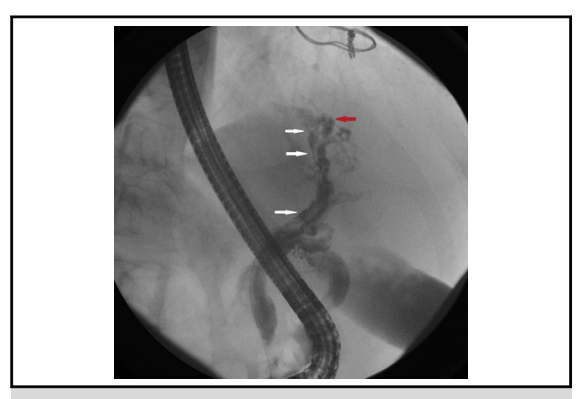

Multifocal strictures and dilatations of intrahepatic bile ducts on endoscopy.

\section{Central Message}

Sclerosing cholangitis in critically ill patients is a severe complication after cardiac surgery. Liver transplantation remains the only curative option but is rarely feasible.

\section{Perspective}

Sclerosing cholangitis in critically ill patients is an underestimated complication in cardiac surgery. Cardiac surgeons need to become familiar with it because of the exceptionally grim prognosis. Early ERCP is the only palliative lifeprolonging intervention for most patients. Few patients will be able to undergo curative liver transplantation.

See Editorial Commentary page 913.
From the ${ }^{\mathrm{a}}$ Department of Thoracic and Cardiovascular Surgery, and ${ }^{\mathrm{b}}$ Faculty of Medicine, Julius-Maximilians-University, Würzburg, Germany.

I.S. and D.R. contributed equally to this work.

Received for publication Feb 14, 2016; revisions received April 4, 2017; accepted for publication April 13, 2017; available ahead of print May 26, 2017.

Address for reprints: Ivan Aleksic, MD, PhD, Klinik für Thorax-, Herz- und Thorakale Gefäßchirurgie, Universitätsklinikum Würzburg, Oberdürrbacher Strasse 6, Würzburg 97080, Germany (E-mail: Aleksic_I@UKW.de).

$0022-5223 / \$ 36.00$

Copyright (c) 2017 by The American Association for Thoracic Surgery

http://dx.doi.org/10.1016/j.jtcvs.2017.04.041
The French surgeon Delbet was the first to describe sclerosing cholangitis as a fibrosing inflammatory state of the

Scanning this QR code will take you to the article title page. 


\section{Abbreviations and Acronyms \\ ALP = alkaline phosphatase \\ AVR $=$ aortic valve replacement \\ $\mathrm{CABG}=$ coronary artery bypass grafting \\ $\mathrm{ECMO}=$ extracorporeal membrane oxygenation \\ $\mathrm{ERCP}=$ endoscopic retrograde cholangiopancreatography \\ $\mathrm{GE}=$ gastroenterology \\ GGT = gamma glutamyl transpeptidase \\ IABP $=$ intra-aortic balloon pump}

biliary tract leading to obstruction. The causes of secondary sclerosing cholangitis normally can be identified and include massive surgical trauma, chemical intoxication, obstructive, infectious, immunologic, and ischemic conditions. ${ }^{1}$

Two types of secondary sclerosing cholangitis portend a particularly poor outcome: acquired immune deficiency syndrome cholangiopathy and sclerosing cholangitis in critically ill patients. The causative cascade of sclerosing cholangitis in critically ill patients is believed to be ischemia to the biliary tree with consecutive bacterial colonization leading to destructive biliary changes. ${ }^{2}$ However, various other causes have been described (Table 1). Most of these severely ill patients died before a diagnosis was established, and perhaps the development of intensive care medicine per se is responsible for the increasing observation of sclerosing cholangitis in critically ill patients.

The incidence and outcome of this disease in patients undergoing cardiac surgery have not been addressed so far. Few reports have included critically ill patients with sclerosing cholangitis after cardiac surgery, ${ }^{2-5}$ but they did not study these patients exclusively.

The aim of this retrospective analysis was to describe the key features of the clinical course of sclerosing cholangitis in critically ill patients undergoing cardiac surgery, compare them with matched controls, highlight important management aspects, and alert cardiac surgeons to this underdiagnosed disease in complicated cases with long-term intensive care unit therapy after cardiac surgical intervention.

\section{MATERIALS AND METHODS}

The study was approved by the local ethics committee. Individual patient consent was waived.

A retrospective search for the diagnosis "secondary sclerosing cholangitis" and "liver and/or hepatic failure" in all adults (aged 18-93 years) who underwent cardiac surgery with the use of extracorporeal circulation from April 2007 to March 2016 was conducted. A typical laboratory value pattern of elevated bilirubin, gamma glutamyl transpeptidase (GGT), and alkaline phosphatase (ALP) levels combined with only moderately elevated aspartate and alanine aminotransferases led to a gastroenterology (GE) consult. The suspected diagnosis was confirmed by endoscopic retrograde cholangiopancreatography (ERCP) or autopsy. In addition, data on amylase and lipase were collected. Patients with postoperative ischemic
TABLE 1. Possible causes of secondary sclerosing cholangitis

\begin{tabular}{|c|c|c|}
\hline Etiology & Cause & Pathogenesis \\
\hline $\begin{array}{l}\text { Chronic } \\
\text { obstruction }^{6}\end{array}$ & $\begin{array}{l}\text { Biliary strictures } \\
\text { Neoplasms } \\
\text { Choledocholithiasis }\end{array}$ & $\begin{array}{l}\text { Recurrent } \\
\text { cholangitis }\end{array}$ \\
\hline Immunologic & $\begin{array}{l}\text { Autoimmune pancreatitis }{ }^{7} \\
\text { Mast cell cholangiopathy }{ }^{6}\end{array}$ & Inflammation \\
\hline Infection & $\begin{array}{l}\text { Cytomegalovirus }^{8} \\
\text { Cryptosporidiosis in patients with } \\
\text { AIDS }^{8}\end{array}$ & Inflammation \\
\hline Ischemia & $\begin{array}{l}\text { Hepatic artery thrombosis } \\
\text { Hepatic artery chemotherapy } \\
\text { infusion } \\
\text { Embolization therapy }^{10} \\
\text { Systemic vasculitis }\end{array}$ & \\
\hline $\begin{array}{l}\text { Ischemic-like } \\
\text { cholangiopathy }\end{array}$ & Patients with ARDS ${ }^{2}$ & Unknown \\
\hline Toxic & $\begin{array}{l}\text { Alcohol or formaldehyde } \\
\text { instillation in bile ducts }\end{array}$ & $\begin{array}{c}\text { Epithelial } \\
\text { injury }\end{array}$ \\
\hline
\end{tabular}

$\overline{A I D S}$, Acquired immunodeficiency syndrome; $A R D S$, adult respiratory distress syndrome.

hepatitis as indicated by high transaminase levels and later increment of cholestatic parameters and lack of ERCP were excluded from analysis.

A group of 36 patients were identified for comparison to perform a 3:1 matching. These patients were matched for age, preoperative American Society of Anesthesiology class, body mass index, use of any mechanical circulatory support, need for postoperative dialysis, baseline bilirubin, ALP and GGT, and preoperative European System for Cardiac Operative Risk Evaluation (Table 2). Ultrasound excluded gallstones and confirmed normal caliber of the common bile duct in all critically ill patients with sclerosing cholangitis, and an additional computed tomography was performed in 2 patients. Stenosis of the hepatic artery and obstruction of the hepatic veins or the portal vein were excluded by duplex sonography.

All parameters were extracted from the hospital database, including indication for surgery, preoperative medical data, comorbidities, potential confounding factors for the development of sclerosing cholangitis in critically ill patients (Table 2), length of intensive care unit stay, total length of stay and time until death, laboratory values, intraoperative parameters, inotropic requirements, ventilation times, renal replacement therapy, any mechanical circulatory support, microbiology results, and ultrasound and ERCP studies.

Endoscopic therapy consisted of sphincterotomy with removal of any occlusive material from the common bile duct using a balloon or basket and dilation of any gross stenosis (Figure 1). All patients with evidence of bacterial cholangitis by cultures from biliary fluids and no signs of sclerosing cholangitis receiving ERCP were treated with broad-spectrum antibiotics.

\section{Statistical Analysis}

Data are presented as median \pm interquartile range. For matching purposes, the standardized difference (Cohen's D) with 95\% upper and lower confidence intervals was calculated. The Mann-Whitney $U$ test was used for direct comparison between the critically ill patients with sclerosing cholangitis and the matching group and the Fisher test when appropriate (Table 3). The statistical package $\mathrm{R}$ was used for all calculations.

\section{RESULTS}

Between April 2007 and March 2016, 8625 patients underwent operation using the heart-lung machine. By using 
TABLE 2. Matching criteria between critically ill patients with sclerosing cholangitis $(N=12)$ and comparison patients $(N=36)$

\begin{tabular}{lccc}
\hline \multicolumn{1}{c}{ Matching criterion } & $\begin{array}{c}\text { Sclerosing cholangitis in } \\
\text { critically ill patients }(\mathbf{N}=\mathbf{1 2})\end{array}$ & $\begin{array}{c}\text { Comparison } \\
\text { patients }(\mathbf{N}=\mathbf{3 6})\end{array}$ & $\begin{array}{c}\boldsymbol{P} \text { value (lower to } \\
\text { upper 95\% } \mathbf{C I})\end{array}$ \\
\hline Age, y & $71(59.8-75.5)$ & $69(60.8-78)$ & $1.0(-7.0$ to 8$)$ \\
ASA class & $3.0(3.0-3.3)$ & $3.0(3.0-4.0)$ & $0.12(-1.0$ to 0.0$)$ \\
$\quad$ Class 2 (N, \%) & $1(8.3 \%)$ & - & $19(52.8 \%)$ \\
Class 3 (N, \%) & $8(66.7 \%)$ & $17(47.2 \%)$ & $0.14 *$ \\
Class 4 (N, \%) & $3(25 \%)$ & $28.4(26.1-29.9)$ & $0.06(-5.1$ to 0.1$)$ \\
BMI & $25.3(22.2-28.4)$ & $5.3(3.2-9.5)$ & $0.49(-2.1$ to 4.2$)$ \\
euroSCORE II & $6.7(4.7-12.5)$ & $21(58 \%)$ & $0.74(0.16-3.28)^{*}$ \\
Any mechanical circulatory support (IABP or ECMO) & $6(50 \%)$ & $21(58.3 \%)$ & $0.49(0.43-14.17)^{*}$ \\
Postoperative dialysis & $9(75 \%)$ & $0.5(0.4-0.7)$ & $0.70(-0.3$ to 0.9$)$ \\
Baseline bilirubin & $0.8(0.3-1.4)$ & $67(58-86)$ & $0.026(-34$ to -3$)$ \\
Baseline ALP & $43(36-73)$ & $41(27-118)$ & $0.51(-39$ to 16$)$ \\
Baseline GGT & $41(23-69)$ &
\end{tabular}

Data are given as median with interquartile range or absolute values with percentages for categoric data. Age, BMI, ASA class, euroSCORE II, baseline bilirubin, ALP, and GGT were tested with the Mann-Whitney $U$ test. CI, Confidence interval; ASA, American Society of Anesthesiology; BMI, body mass index; euroSCORE, European System for Cardiac Operative Risk Evaluation; IABP, intra-aortic balloon pump; ECMO, extracorporeal membrane oxygenation; $A L P$, alkaline phosphatase; $G G T$, gamma glutamyl transpeptidase. *Fisher exact test.

the search strategy outlined before either screening diagnosis was identified in 192 patients. Of those, 12 patients $(6.25 \%)$ were finally diagnosed with sclerosing cholangitis, yielding an incidence of $0.14 \%$ (12/8625). In all other patients, a final diagnosis could not be established from this retrospective review. All 12 critically ill patients with

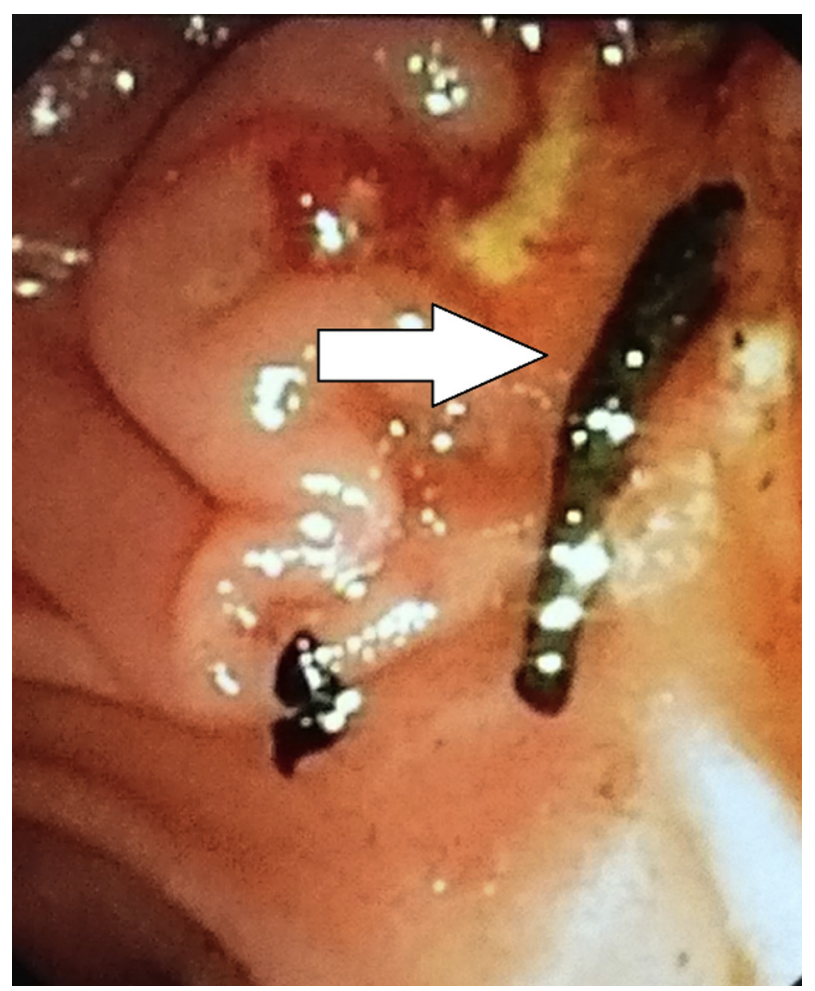

FIGURE 1. Bile cast (white arrow) within lumen of duodenum after extraction during ERCP in a critically ill patient with sclerosing cholangitis. sclerosing cholangitis had no evidence of preexisting hepatobiliary, pancreatic, or inflammatory bowel disease, and had normal cholestatic laboratory parameters before surgery.

There were 9 men and 3 women, with a median age of 71 years (range, 59.8-75.5 years). The matched comparison group consisted of 26 men and 10 women $(P=1.00)$ with a median age of $69(60.8-78)$ years $(P=1.00)$. Preoperative American Society of Anesthesiology, body mass index, and European System for Cardiac Operative Risk Evaluation II were similar (Tables 2 and 3). Five patients underwent coronary artery bypass grafting (CABG) and were matched to 15 comparison patients who underwent $\mathrm{CABG}$, and 1 patient who underwent $\mathrm{CABG}$ plus aortic valve replacement (AVR) was matched to 3 comparison patients with the same procedure. One patient who underwent CABG with concomitant AVR and hemiarch replacement was matched to a patient who underwent a David procedure plus CABG, a patient with double valve replacement, and a patient with CABG and AVR. One study patient who underwent the David procedure was matched to 1 patient who underwent the David procedure, 1 patient who underwent the modified Bentall, and 1 patient who received ascending aorta replacement. The study patient with tricuspid valve replacement plus CABG was matched to 1 patient with tricuspid valve repair plus CABG, 1 patient with mitral and tricuspid valve repair, and 1 patient with double valve replacement (AVR and mitral valve replacement).

One patient who received redo root replacement plus CABG was matched to 2 patients who received redo root replacement and 1 patient with contained rupture of the ascending aorta, 1 patient who received orthotopic heart transplantation was matched to 2 patients who received heart transplantations and 1 patient who received the David procedure plus $\mathrm{CABG}$, and 1 patient who received repair of 
TABLE 3. Standardized differences for matching criteria (Cohen's D) before and after matching with lower and upper $95 \%$ confidence intervals

\begin{tabular}{lcccc}
\hline Matching criterion & $\begin{array}{c}\text { Critically ill patients } \\
\text { with sclerosing } \\
\text { cholangitis }(\mathbf{N}=\mathbf{1 2})\end{array}$ & $\begin{array}{c}\text { Comparison } \\
\text { patients } \\
\text { (N= 36) }\end{array}$ & $\begin{array}{c}\text { Cohen's D before } \\
\text { matching (lower and } \\
\text { upper 95\% } \mathbf{~ C I})\end{array}$ & $\begin{array}{c}\text { Cohen's D after } \\
\text { matching }(\mathbf{l o w e r} \text { and } \\
\text { upper 95\% } \mathbf{~ C I})\end{array}$ \\
\hline Age, y & $68.9 \pm 10.7$ & $68.7 \pm 10.6$ & $0.08(-0.47$ to 0.63$)$ & $0.02(-0.63$ to 0.67$)$ \\
ASA class & $3.2 \pm 0.6$ & $3.5 \pm 0.5$ & $-0.61(-1.35$ to 0.06$)$ & $-0.56(-1.23$ to 0.1$)$ \\
BMI & $26.3 \pm 5.4$ & $28.2 \pm 2.9$ & $-0.51(-1.03$ to 0.16$)$ & $-0.43(-1.09$ to 0.23$)$ \\
euroSCORE II & $8.8 \pm 6.9$ & $8.1 \pm 7.5$ & $0.16(-0.39$ to 0.71$)$ & $0.1(-0.56$ to 0.75$)$ \\
Any mechanical circulatory support (IABP or ECMO) & $0.5 \pm 0.52$ & $0.58 \pm 0.5$ & $-0.58(-1.14$ to -0.03$)$ & $-0.16(-0.82$ to 0.49$)$ \\
Postoperative dialysis & $0.75 \pm 0.78$ & $0.58 \pm 0.5$ & $0.49(-0.42$ to 1.2$)$ & $0.35(-0.31$ to 1.01$)$ \\
Baseline bilirubin & $1.1 \pm 1.6$ & $0.98 \pm 1.81$ & $0.44(-0.11$ to 1.00$)$ & $0.54(-0.12$ to 1.2$)$ \\
Baseline ALP & $53 \pm 23$ & $84 \pm 58$ & $-0.67(-1.24$ to -0.1$)$ & $-0.7(-1.37$ to -0.03$)$ \\
Baseline GGT & $49 \pm 36$ & $80 \pm 86$ & $-0.53(-1.09$ to 0.04$)$ & $-0.48(-1.14$ to 0.19$)$ \\
\hline
\end{tabular}

Data are presented as mean \pm standard deviation. For categoric data, the mean is the percentage. $C I$, Confidence interval; $A S A$, American Society of Anesthesiology; $B M I$, body mass index; euroSCORE, European System for Cardiac Operative Risk Evaluation; $I A B P$, intra-aortic balloon pump; $E C M O$, extracorporeal membrane oxygenation; $A L P$, alkaline phosphatase; GGT, glutamyl transpeptidase.

aortic dissection type A was matched to 1 patient with other dissection type A, 1 patient who received the modified Bentall, and 1 patient who received ascending aorta plus aortic arch replacement. No patient had endocarditis, and only 3 patients underwent operation as an emergency procedure compared with 17 patients in the control group $(P=.31)$.

In the study group, 2 patients had poor right ventricular function before surgery as evidenced by preoperative echocardiography, and 1 patient required intraoperative cardiopulmonary resuscitation for hemodynamic stabilization. In contrast, 7 patients in the comparison group had impaired right ventricular function preoperatively $(P=1.00)$. The duration of all procedures, time on bypass, and crossclamp time are shown in Table 4.

Mechanical circulatory support was initiated intraoperatively because of failure to wean from cardiopulmonary bypass. The first step always was transfemoral insertion of an intra-aortic balloon pump (IABP). If this did not suffice for hemodynamic stabilization, intraoperative venoarterial extracorporeal membrane oxygenation (ECMO) via the femoral vein and an 8-mm vascular graft anastomosed to the aorta in an end-to-side fashion $(\mathrm{N}=2)$ tunneled to the right third intercostal space or to the right subclavian artery $(\mathrm{N}=1)$ were used. Two patients required ECMO therapy via femoral vein and subclavian artery on postoperative days 1 and 8, respectively. In all patients who received ECMO, the venous cannula was inserted via a femoral vein and positioned below the right atrium in the inferior vena cava as confirmed by transesophageal echocardiography. Of those, 4 patients had an IABP at the same time and 1 patient received implantation of a left ventricular assist device (HeartMate II, Thoratec, Pleasanton, Calif). Proper IABP position was checked by transesophageal echocardiography or radiograph daily. In the comparison group, 14 patients required ECMO support via the femoral vein and the femoral artery $(\mathrm{N}=9)$ or subclavian artery $(\mathrm{N}=5)$ with concomitant IABP support. Incidence and duration of support were similar (Table 4).

TABLE 4. Intraoperative parameters, duration of mechanical circulatory support, dialysis, and vasoactive drugs in critically ill patients with sclerosing cholangitis $(\mathrm{N}=12)$ and controls $(\mathrm{N}=36)$

\begin{tabular}{|c|c|c|c|}
\hline Parameter & $\begin{array}{l}\text { Critically ill patients with sclerosing } \\
\text { cholangitis group }(N=12)\end{array}$ & Comparison group $(N=36)$ & $P$ value \\
\hline Procedure time (min) & $288(251-327.8)$ & $260(214.3-376)$ & .39 \\
\hline Perfusion time (min) & $170.5(119.8-217.5)$ & $143.5(95-214.8)$ & .28 \\
\hline Crossclamp time (min) & $92.5(69.8-137.3)$ & $95(50.5-133)$ & .67 \\
\hline $\operatorname{IABP}(\mathrm{N})$ & $5(41.7 \%)$ & $17(47.2 \%)$ & 1.00 \\
\hline IABP duration (d) & $0(0-5.8)$ & $0(0-3.3)$ & .94 \\
\hline $\operatorname{ECMO}(\mathrm{N})$ & $5(41.7 \%)$ & $14(38.9 \%)$ & 1.00 \\
\hline ECMO duration (d) & $0(0-6.3)$ & $0(0-2.3)$ & .58 \\
\hline Duration (h) of norepinephrine & $356.5(264.5-621)$ & $68(15-132.5)$ & .003 \\
\hline Duration (h) of epinephrine & $15(5-86.5 ; \mathrm{N}=6)$ & $12(4.5-27 ; \mathrm{N}=23)$ & .36 \\
\hline Duration (h) of enoximone & $177(124.3-249.5)$ & $48.5(12-81)$ & $<.001$ \\
\hline Duration (h) of vasopressin & $52(32-84 ; \mathrm{N}=8)$ & $19(11-33 ; \mathrm{N}=21)$ & .17 \\
\hline Duration of dialysis (d) & $5.5(0.8-24)$ & $57(1-15)$ & .95 \\
\hline
\end{tabular}

Data are given as median with interquartile range or absolute values with percentages for categoric data. IABP, Intra-aortic balloon pump; $E C M O$, extracorporeal membrane oxygenation. 
TABLE 5. Postoperative laboratory values of critically ill patients with sclerosing cholangitis $(\mathbf{N}=12)$

\begin{tabular}{|c|c|c|c|c|c|}
\hline Parameter & $\begin{array}{c}\text { Reference range of } \\
\text { laboratory }\end{array}$ & $\begin{array}{c}\text { Baseline after } \\
\text { surgery }\end{array}$ & $\begin{array}{c}\text { Peak values } \\
\text { after surgery }\end{array}$ & $\begin{array}{c}\text { Range for peak } \\
\text { values }\end{array}$ & $\begin{array}{l}\text { Peak after } \\
\text { surgery (d) }\end{array}$ \\
\hline Bilirubin $(\mathrm{mg} / \mathrm{dL})$ & $0.1-1.2$ & $1.1 \pm 1.1$ & $22.1 \pm 12.6$ & $0.7-35.8$ & $40 \pm 26$ \\
\hline ALP (U/L) & $40-130$ & $52 \pm 24$ & $1228 \pm 1751$ & $207-5797$ & $30 \pm 21$ \\
\hline GGT (U/L) & $\leq 60$ & $46 \pm 21$ & $949 \pm 841$ & $81-2226$ & $27 \pm 19$ \\
\hline GOT (U/L) & $\leq 50$ & $87 \pm 129$ & $1065 \pm 865$ & $47-2251$ & $18 \pm 25$ \\
\hline GPT (U/L) & $\leq 50$ & $64 \pm 143$ & $599 \pm 325$ & $28-1000$ & $18 \pm 24$ \\
\hline Amylase (U/L) & $\leq 110$ & $105 \pm 16$ & $245 \pm 243$ & $26-780$ & $16 \pm 24$ \\
\hline Lipase (U/L) & $13-60$ & $107 \pm 30$ & $419 \pm 747$ & $14-2409$ & $16 \pm 24$ \\
\hline
\end{tabular}

All values expressed as mean \pm standard deviation where appropriate. $A L P$, Alkaline phosphatase; GGT, gamma glutamyl transferase; GOT, aspartate aminotransferase; GPT, alanine aminotransferase.

All critically ill patients with sclerosing cholangitis were weaned from IABP support. Three patients with ECMO were weaned on postoperative days 7,17 , and 10 during implant of a ventricular assist device. In the control group, 4 patients were successfully weaned from ECMO, but only 2 patients were discharged.

All patients required vasoconstrictive support by norepinephrine. Critically ill patients with sclerosing cholangitis required norepinephrine and enoximone for a longer period of time than patients in the comparison group. The duration of application is provided in Table 4 for both groups. In the group of critically ill patients with sclerosing cholangitis, enoximone plus norepinephrine was used in 10 patients as opposed to 19 patients in the comparison group. Of those 10 patients, 6 were treated with norepinephrine plus epinephrine and enoximone, and 8 required vasopressin in addition to norepinephrine plus enoximone or epinephrine. A total of 17 patients in the comparison group required vasopressin in addition to norepinephrine plus enoximone or epinephrine $(P=.77)$.

All but 2 critically ill patients with sclerosing cholangitis underwent 1 to 13 operative revisions (median 3 [2.5-6] for all patients) for bleeding or wound-healing problems and mediastinitis. A total of 55 revisions after the primary surgical intervention was recorded. Of those, 14 (25.5\%) were rethoracotomies, $34(62 \%)$ were vacuum-assisted closure (VAC) interventions, 4 (7.3\%) were bleedings from the arterial ECMO cannula, $2(3.6 \%)$ were hemicolectomies for ischemic colon, and 1 was a liver transplantation $(1.8 \%)$. In contrast, only 20 patients in the comparison group underwent a median of 1 (0-2) operative revisions $(P=.003)$. A total of 65 revisions for all patients in the comparison group were recorded; 21 were VAC interventions, and 30 were rethoracotomies. Analysis of ventilator parameters showed a longer mean respirator time in the group of critically ill patients with sclerosing cholangitis (628.5 hours [377.3-883] vs 25 hours [9.8-117.5]; $P<.001)$.

Eight critically ill patients in the group with sclerosing cholangitis required renal replacement therapy for 5.5 (0.8-24) days, and 1 of them was on preoperative dialysis.
A total of 21 patients in the comparison group required renal replacement therapy for $5(1-15)$ days $(P=.95)$, with 2 patients requiring preoperative dialysis.

Sclerosing cholangitis in critically ill patients was diagnosed $25 \pm 21$ days after the initial operation with ECC. In all critically ill patients with sclerosing cholangitis, an increase in liver function test results was observed, particularly ALP, GGT, and bilirubin (Table 5).

Increases of ALP, GGT, and bilirubin were more pronounced in the critically ill patients with sclerosing cholangitis than in the comparison group. ALP peaked at a median of $751.5 \mathrm{U} / \mathrm{L}(372-1722.3)$ versus $80.5 \mathrm{U} / \mathrm{L}(53.5-122$; $P<.001)$, GGT peaked at $1082.3 \mathrm{U} / \mathrm{L}(259.5-2265.7)$ versus 53.8 U/L (35.1-146; $P<.001)$, and bilirubin peaked at $23.3 \mathrm{mg} / \mathrm{dL}$ (14.4-32.9) versus $1 \mathrm{mg} / \mathrm{dL}$ (0.6-2.7; $P<.001)$. All postoperative laboratory values of critically ill patients with sclerosing cholangitis are provided in Table 5.

A total of 11 critically ill patients with sclerosing cholangitis died: 5 of multiorgan failure due to sepsis, 2 of multiorgan failure due to pneumonia, 3 of liver failure, and 1 of pneumonia. Average survival time was $45 \pm 26$ days (range, 22-108 days). One patient underwent successful liver transplantation at the Julius-Maximilians-University and was discharged after 85 days. A total of 12 of 36 patients in the comparison group died: 9 of multiorgan failure due to sepsis and 3 of cardiac failure $(P<.001$, Fisher exact test).

\section{DISCUSSION}

Abnormal liver function test results will develop in up to $30 \%$ of patients in intensive care units within the first 48 hours. ${ }^{12}$ Critically ill patients with sclerosing cholangitis will show persistent cholestasis despite no preexisting hepatic or biliary disease. The most commonly discussed cause is ischemia of the bile duct epithelium due to hypoperfusion of the perivascular plexus followed by biliary cast formation and facultative consecutive biliary infection. ${ }^{2,13,14}$ Sclerosing cholangitis in critically ill patients is a progressive disease with anatomic damage of the biliary tree. On a cellular level, downregulation of the canalicular phospholipid export pump multidrug resistance protein 
3 due to ischemia, endotoxins, and proinflammatory cytokines is considered as a potential explanation for sclerosing cholangitis in critically ill patients. ${ }^{15}$ The ensuing deficiency of phospholipids in bile causes injury of the bile ducts, pericholangitis, and periductal fibrosis, eventually leading to sclerosing cholangitis in a mouse model. ${ }^{16}$

The diagnosis of sclerosing cholangitis in critically ill patients is confirmed by ERCP (Figure 2), generally after GE consultation or autopsy. Less than 100 cases have been reported, mostly from Germany., ${ }^{2,13}$ Only recently has the syndrome been reported in a patient from the United Kingdom. ${ }^{17}$

All patients had severe life-threatening illness necessitating prolonged intensive care and respirator therapy, needed vasopressors, had biliary casts in intrahepatic bile ducts on ERCP, and had recurrent symptoms of cholangitis despite adequate ERCP therapy with continuing destruction of the biliary tree. Biliary casts were extracted in all ERCP procedures. Jaeger and coworkers ${ }^{18}$ showed that ERCP and extraction of the bile duct occluding material resulted in clinical and biochemical improvement of cholestasis. However, the progressive destruction of the biliary tree cannot be prevented by ERCP. It remains a purely palliative procedure.

Severe cardiac disease not amenable to interventional therapy was the reason for cardiac surgical intervention in our patients. All patients experienced prolonged respirator support in contrast to the comparison group. Critically ill patients with sclerosing cholangitis required prolonged

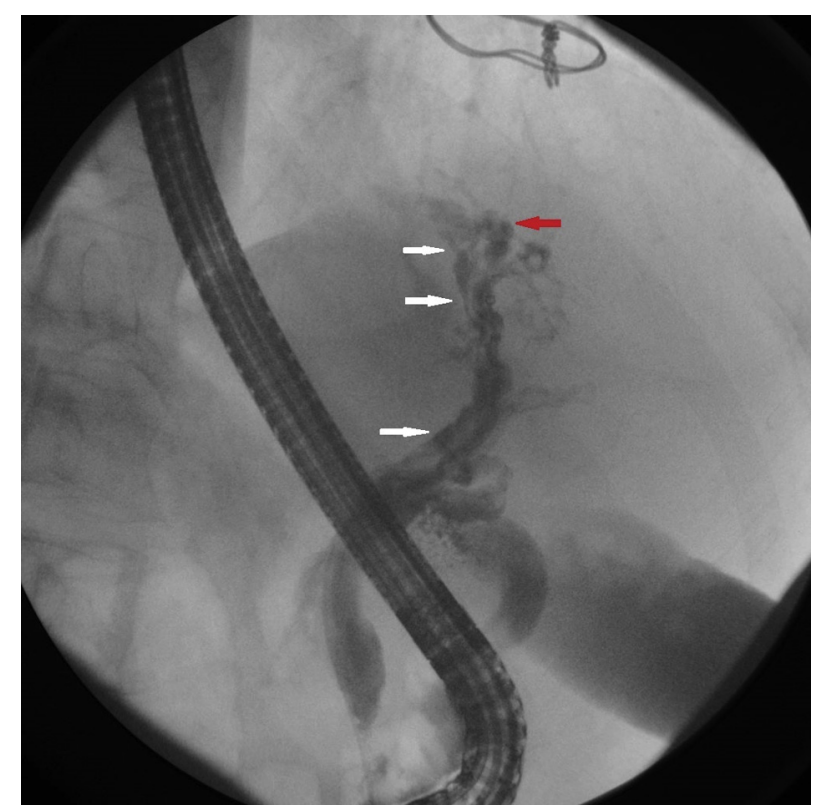

FIGURE 2. ERCP with multifocal strictures, contrast dye deficits (white arrows), and irregular dilatations in intrahepatic bile ducts (red arrow) indicating progressed sclerosing cholangitis in a critically ill patient. vasoconstrictor and inotropic support as evidenced by longer duration of norepinephrine, epinephrine, and enoximone therapy compared with controls. Hepatosplanchnic perfusion is known to become compromised, in particular if epinephrine and norepinephrine are combined ${ }^{14}$ as observed in our study cohort, and favors ischemia of the intestines and bile duct system.

An inconspicuous ultrasound should not preclude ERCP if sclerosing cholangitis in critically ill patients is clinically suspected by the laboratory value pattern and clinical course described because the echogenic casts may mimic a normal bile duct system. ${ }^{4}$ The necessity for an invasive procedure and the delayed maximum of elevation of ALP, GGT, and bilirubin as markers of sclerosing cholangitis in critically ill patients are the cause for the observed average delay of 25 days until establishing the diagnosis in our study group. Sclerosing cholangitis in critically ill patients probably is often overlooked.

Kulaksiz and colleagues ${ }^{4}$ described renal replacement therapy and elevated Model of End-Stage Liver Disease scores as risk factors for a higher mortality in sclerosing cholangitis in critically ill patients. The incidence of dialysis was similar between both groups in our report.

Kirchner and colleagues ${ }^{19}$ concluded from 11 patients undergoing liver transplantation that critically ill patients with sclerosing cholangitis with a history of major trauma are more suitable candidates than those without because they were healthy before the trauma. Kulaksiz and coworkers ${ }^{4}$ estimated survival free of liver transplantation to be $55 \%$ at 1 year and $14 \%$ at 6 years in critically ill patients with sclerosing cholangitis. Median survival free of liver transplantation ranges between 1.1 and 6 years. ${ }^{1,4}$ Only 1 patient described in this article had a presumably more benign history of trauma before development of sclerosing cholangitis in critically ill patients, and just 2 patients were evaluated for liver transplantation. The patient with abdominal trauma was turned down by 2 different liver transplant programs in accordance with the data published by Kirchner and coworkers, ${ }^{19}$ whereas the other patient underwent transplantation after hemicolectomy for ischemic colitis.

\section{Study Limitations}

We have retrospectively described a specific subset of critically ill patients developing sclerosing cholangitis after cardiac surgery. The disease has not been in the focus of cardiac surgeons so far. Therefore, the level of suspicion is not high enough, causing delayed requests for GE consultation and consecutive ERCP. We cannot be certain that all patients excluded for ischemic hepatitis were not critically ill patients with sclerosing cholangitis. This is because most of these patients did not undergo ERCP, which would have established the diagnosis. Because of the retrospective character of the study, we performed a 3:1 matching, but a 
prospective study with "all-comer ERCP" clearly would yield harder data on this disease in the context of cardiac surgery.

Furthermore, the time span between surgery and diagnosis of sclerosing cholangitis in critically ill patients is long, and we might increase our patients' length of survival with earlier ERCP in the future, as evidenced in the literature, ${ }^{18}$ although it is a strictly palliative procedure.

\section{CONCLUSIONS}

Sclerosing cholangitis in critically ill patients after cardiac surgery carries a dismal prognosis. Cardiac surgical patients presenting with a history of biliary obstruction, human immunodeficiency virus infection, and hepatic ischemia, and requiring prolonged ventilation, several revisions, or prolonged inotropic support postoperatively require a higher level of alertness for changes in liver function on the side of the surgical team. Otherwise, the diagnosis often will be delayed because of the necessity for invasive ERCP. However, early ERCP is beneficial for clinical improvement of these patients by allowing for better bile drainage, but liver transplantation is the only curative option. Many cardiac surgical patients are too old and sick for transplantation candidacy. ERCP remains the only symptomatic palliative life-prolonging option for the majority of our patients.

\section{Conflict of Interest Statement}

Authors have nothing to disclose with regard to commercial support.

\section{References}

1. Gossard AA, Angulo P, Lindor KD. Secondary sclerosing cholangitis: a comparison to primary sclerosing cholangitis. Am J Gastroenterol. 2005;100:1330-3.

2. Gelbmann CM, Rümmele P, Wimmer M, Hofstädter F, Göhlmann B, Endlicher E, et al. Ischemic-like cholangiopathy with secondary sclerosing cholangitis in critically ill patients. Am J Gastroenterol. 2007;102:1221-9.

3. Voigtländer T, Negm AA, Schneider AS, Strassburg CP, Manns MP, Wedemeyer J, et al. Secondary sclerosing cholangitis in critically ill patients:
Model of End-Stage Liver Disease score and renal function predict outcome. Endoscopy. 2012;44:1055-8.

4. Kulaksiz H, Heuberger D, Engler S, Stiehl A. Poor outcome in progressive sclerosing cholangitis after septic shock. Endoscopy. 2008;40:214-8.

5. Esposito I, Kubisova A, Stiehl A, Kulaksiz H, Schirrmacher P. Secondary sclerosing cholangitis after intensive care unit treatment: clues to the histopatholog ical differential diagnosis. Virchows Arch. 2008;453:339-45.

6. Baron TH, Koehler RE, Rodgers WH, Fallon MB, Ferguson SM. Mast cell cholangiopathy: another cause of sclerosing cholangitis. Gastroenterology. 1995;109: 1677-81.

7. Yusuf TE, Baron TH. AIDS cholangiopathy. Curr Treat Options Gastroenterol. 2004; $7: 111-7$

8. Fischer A, Miller CH. Ischemic-type biliary strictures in liver allografts: the Achilles heel revisited? Hepatology. 1995;21:63-9.

9. Hohn D, Melnick J, Stagg R, Altman D, Friedman M, Ignoffo R, et al. Biliary sclerosis in patients receiving hepatic arterial infusions of floxuridine. J Clin Oncol. 1985;3:98-102.

10. Makuchi M, Sukigara M, Mori T, Kobayashi J, Yamazaki S, Hasegawa H, et al. Bile duct necrosis: complication of transcatheter hepatic arterial embolization. Radiology. 1985;156:331-4.

11. Sahin M, Eryilmaz R, Bulbuloglu E. The effect of scollicidal agents on liver and biliary tree (experimental study). J Invest Surg. 2004;17:323-6.

12. Horvatits T, Trauner M, Fuhrmann V. Hypoxic liver injury and cholestasis in critically ill patients. Curr Opin Crit Care. 2013;19:128-32.

13. Ruemmele P, Hofstaedter F, Gelbmann CM. Secondary sclerosing cholangitis Nat Rev Gastroenterol Hepatol. 2009;6:287-95.

14. Krejci V, Hiltebrand LB, Sigurdsson GH. Effects of epinephrine, norepinephrine, and phenylephrine on microcirculatory blood flow in the gastrointestinal tract in sepsis. Crit Care Med. 2006;34:1456-63.

15. Trauner M, Fickert P, Wagner M. MDR3 (ABCB4) defects: a paradigm for the genetics of adult cholestatic syndromes. Semin Liver Dis. 2007;27:77-98.

16. Fickert P, Fuchsbichler A, Wagner M, Zollner G, Kaser A, Tilg H, et al. regurgitation of bile acids from leaky bile ducts causes sclerosing cholangitis in Mdr2 (ABCB4) knockout mice. Gastroenterology. 2004;127:261-74.

17. Patel KV, Zaman S, Chang F, Wilkinson M. Rare case of severe cholangiopathy following critical illness. BMJ Case Rep. 2014;2014: http://dx.doi.org/10. 1136/bcr-2013-202476.

18. Jaeger C, Mayer G, Henrich R, Gossner L, Rabenstein T, May A, et al. Secondary sclerosing cholangitis after long-term treatment in an intensive care unit: clinical presentation, endoscopic findings, treatment and follow-up. Endoscopy. 2006;38: $730-4$.

19. Kirchner GI, Scherer MN, Obed A, Ruemmele P, Wiest R, Froh M, et al. Outcome of patients with ischemic-like cholangiopathy with secondary sclerosing cholangitis after liver transplantation. Scand J Gastroenterol. 2011;46: 471-8.

Key Words: cardiac surgery, extracorporeal circulation, intensive care medicine, secondary sclerosing cholangitis 